\title{
Evaluation of Innovation and Entrepreneurship Education Capability in Colleges and Universities Based on Entropy TOPSIS-A Case Study
}

\author{
Liangyuan Quan ${ }^{1}$ \\ Hui Zhou ${ }^{2}$ \\ Hohai University Nanjing Tech University \\ Çukurova University
}

\begin{abstract}
At present, China has stepped into the era of the economy of everyone and mass entrepreneurship. Colleges and universities as the carrier of the era of mass entrepreneurship, and innovation and entrepreneurship education presents increasingly important significance. Based on the data of 9 colleges and universities in Jiangsu Province in 2016, the index system of innovation and entrepreneurship education capacity is established, and the model is established by entropy TOPSIS method. The empirical analysis is carried out on the level of innovation and entrepreneurship education capacity of 9 colleges and universities. The results show that the main factors that influence the innovative entrepreneurship education capacity include the number of publications published, the number of patents authorized, the entrepreneurial plan contest and the university science park. The resource allocation ability of colleges and universities is different, and the input-output ratio is obviously different.
\end{abstract}

\section{Keywords}

Colleges and Universities $\bullet$ Innovation and Entrepreneurship $•$ Education Capacity $\bullet$ Entropy TOPSIS

\footnotetext{
"This work is supported by Jiangsu Education science 12th five-year plan project (K-c/2015/10, Nanjing, China), Jiangsu University counsellor work seminar special topic (15FYHLX25, Nanjing, China), Jiangsu University counsellor work seminar special topic(16FYHYB020, Nanjing, China), Research project on the ideological and political work of philosophy and social science in Jiangsu (2017SJBFDY361, Nanjing, China), Jiangsu University philosophy, social science, ideological and political work special research project. University (17GLD009, Nanjing, China), National commercial science education scientific research "13th five-year plan" project (SKJYKT-1701, Nanjing, China) and Jiangsu university student village official research project (JSCG1703, Nanjing, China).

${ }^{1}$ Correspondence to: Liangyuan Quan $(\mathrm{PhD})$, School of Business, Hohai University, Nanjing 210012, China; School of Marxism, Nanjing Tech University, Nanjing 211816, China. Email: quanquan_amanda@163.com

${ }^{2}$ School of Biotechnology and Pharmaceutical Engineering, NanJing Tech University, Nanjing 211816, China. Email: kingshb@sina.cn
}

Citation: Quan, L. Y. \& Zhou, H. (2018). Evaluation of Innovation and Entrepreneurship Education Capability in Colleges and Universities Based on Entropy TOPSIS--- A Case Study. Educational Sciences: Theory \& Practice, 18(5), 994-1004. http://dx.doi.org/10.12738/estp.2018.5.003 
At present, as a new engine of economic development and a new way of innovation-driven development strategy under the new normal state, "mass entrepreneurship and innovation" puts forward new ideas, development and requirements for personnel training mode and college education reform. It is an inevitable way to integrate the depth of knowledge and culture, the new force in the times of mass innovation with the mass entrepreneurship and innovation for promoting the innovation and entrepreneurship education capacity of in colleges and universities. In May 2015, the General Office of the State Council issued the Implementation Opinions on Deepening the Reform of Innovation and Entrepreneurship Education in Institutions of Higher Learning on the problems existing in comprehensively deepening the reform of innovation and entrepreneurship education in colleges and universities, in an effort to comprehensively promote the level of innovation and entrepreneurship education in China's colleges and universities. College students, as the main force of innovation and entrepreneurship, shoulder the important mission of realizing the goal of national planning. Under the positive response and vigorous promotion of national colleges and universities, the education and practice of innovation and entrepreneurship of college students in China are in full swing all over the country. After several years of exploration and development, it is necessary to make a periodic analysis and summary on the general situation of college students' innovation and entrepreneurship, and what problems need to be solved and whether they conform to the training objectives of innovation and entrepreneurship education.

Through reviewing the literature related to innovation and entrepreneurship education, it is found that colleges and universities have not yet formed a set of scientific and widely implemented evaluation system of innovation and entrepreneurship education capacity. From the evaluation index system to the quantitative research, it is scarcer to implement the evaluation and improve the ability plan.

Through the investigation of 270 business schools in America and Canada, Vesper concludes that seven factors, such as curriculum, teacher's thesis and works, and social influence, are the key factors influencing the innovation and entrepreneurship education project in colleges and universities (Vesper \& Gartner, 1997). Huang et al., emphasized that the colleges and universities serve as the social function of knowledge production and application adjuster and provided the strategic direction for the development of innovation and entrepreneurship education in many aspects (Huang, Zhao \& Tang, 2015). From the perspective of economic efficiency, Li Jicheng constructed a three-level index system of curriculum, teachers and environmental policy (Li, 2012). Li Yue et al., put forward the four-dimensional index system of target layer, customer layer, process layer, and resource layer (Li \& Wang, 2014). Song et al., established the performance evaluation index system of innovation and entrepreneurship education by expert investigation method and made an evaluation analysis on the quality of innovation and entrepreneurship education of a university in Anhui by AHP model (Song, Xu \& Ning, 2012). Based on the QFD theory, Qin Jingmin constructed the quality mechanism of innovation and entrepreneurship education to analyze the influence factors and structure of innovation and entrepreneurship education and uses DEA-AHP-FAHP evaluation model to analyze the quality of innovation and entrepreneurship education in colleges and universities of Shandong Province (Qin, 2009).

Through combing the previous researches in the literature and combining the present development of innovation and entrepreneurship education in colleges and universities, this study selects 9 colleges and universities in Jiangsu Province as research objects, designs the index system of innovation and entrepreneurship education capacity, and comprehensively evaluates the innovation and entrepreneurship education capacity of 9 colleges and universities with the method of entropy TOPSIS, with a purpose of improving the attention paid to the innovation and entrepreneurship education capacity. Based on this, we can find the best way to constantly develop the innovation and entrepreneurship education capacity of colleges and universities.

\section{Construction of evaluation index system of innovative and entrepreneurial education capacity of colleges and universities}


Table 1

Evaluation Index System of Entrepreneurial Education Capacity in Colleges and Universities

\begin{tabular}{|c|c|c|c|}
\hline Target layer & Criterion layer & Index layer & $\begin{array}{c}\text { Index } \\
\text { code }\end{array}$ \\
\hline \multirow{3}{*}{$\begin{array}{l}\text { Innovation and } \\
\text { entrepreneurship education } \\
\text { capacity in colleges and } \\
\text { universities }\end{array}$} & $\begin{array}{l}\text { Innovation and } \\
\text { entrepreneurship education: } \\
\text { basic environmental ability }\end{array}$ & $\begin{array}{l}\text { Number of innovation and } \\
\text { entrepreneurship publications } \\
\text { Number of authorized patents } \\
\text { Number of initiated innovation } \\
\text { and entrepreneurship projects } \\
\text { (national level) } \\
\text { Grant for innovation and } \\
\text { entrepreneurship projects } \\
\text { (national level) /RMB ten } \\
\text { thousand }\end{array}$ & $\begin{array}{l}\mathrm{X} 1 \\
\mathrm{X} 2 \\
\mathrm{X} 3 \\
\mathrm{X} 4\end{array}$ \\
\hline & $\begin{array}{l}\text { Innovation and } \\
\text { entrepreneurship education: } \\
\text { resource allocation ability }\end{array}$ & $\begin{array}{l}\text { Number of teachers for the } \\
\text { innovation } \\
\text { entrepreneurship course } \\
\text { Number of innovation and } \\
\text { entrepreneurship courses } \\
\text { Number of participants in } \\
\text { innovation } \\
\text { entrepreneurship } \\
\text { (national level) } \\
\text { Number of entrepreneurship } \\
\text { parks and incubators in colleges } \\
\text { and universities }\end{array}$ & $\begin{array}{l}X 5 \\
X 6 \\
X 7 \\
X 8\end{array}$ \\
\hline & $\begin{array}{l}\text { Innovation and } \\
\text { entrepreneurship education: } \\
\text { result performance ability }\end{array}$ & $\begin{array}{l}\text { Number of awards in } \\
\text { Entrepreneurial Planning } \\
\text { Competition (Challenge Cup) } \\
\text { Psychological characteristics of } \\
\text { college students' innovation and } \\
\text { entrepreneurship } \\
\text { Number of incubator } \\
\text { enterprises in entrepreneurship } \\
\text { parks of colleges and } \\
\text { universities } \\
\text { Number of outstanding } \\
\text { innovation } \\
\text { entrepreneurship alumni }\end{array}$ & $\begin{array}{l}\mathrm{X} 9 \\
\mathrm{X} 10 \\
\mathrm{X} 11 \\
\mathrm{X} 12\end{array}$ \\
\hline
\end{tabular}

The empirical analysis of the innovation and entrepreneurship education capacity in colleges and universities is a process of evaluating the social and economic benefits produced by the input factors of innovation and entrepreneurship education and also an important test of the value judgment and development status of the innovation and entrepreneurship education capacity in colleges and universities. Scholars at home and abroad have put forward many index systems about the evaluation of the innovation and entrepreneurship education capacity in colleges and universities, but with different emphases and the degree of complexity, there is no institutionalized and widely-promoted index system. In the evaluation index system of innovation and entrepreneurship education of colleges and universities, American scholar Vesper and others made outstanding research achievements. Based on the principles of subjectivity, scientifically and comparability, and combining with the seven-factor evaluation method put forward by Vesper et al and the research results of domestic scholars on the evaluation of innovation and entrepreneurship education capacity in colleges and universities, the study constructs an evaluation index system of innovation and entrepreneurship education capacity of colleges and universities (Table 1) from the three dimensions of environment basic ability, resource allocation ability and result performance ability, namely, feasibility, efficiency and benefits of innovation and entrepreneurship education in colleges and universities, in order to be comprehensively, objectively and effectively evaluating the current situation and shortcomings of 9 colleges and universities in innovation and 
entrepreneurship education activities in Jiangsu Province.

It can be seen from Table 1 that the evaluation index system for innovation and entrepreneurship education capacity in colleges and universities includes three dimensions: basic environment ability of innovation and entrepreneurship education, resource allocation ability of innovation and entrepreneurship education, innovation and result performance ability of innovation and entrepreneurship education. Among them, the specific measurement indexes of basic environment ability include the number of released innovation and entrepreneurship papers, the number of authorized patents, the number of initiated innovation and entrepreneurship projects (national level), and the grant for innovation and entrepreneurship projects (national level); the specific measurement indexes of resource allocation ability include the number of teachers for the innovation and entrepreneurship course, the number of innovation and entrepreneurship courses, the number of participants in innovation and entrepreneurship projects (national level) and the number of entrepreneurship parks and incubators in colleges and universities; the measurement indexes of result performance ability include the number of awards in Entrepreneurial Planning Competition (Challenge Cup), the psychological characteristics of college students' innovation and entrepreneurship, the number of incubator enterprises in entrepreneurship parks of colleges and universities and the number of outstanding innovation and entrepreneurship alumni.

\section{Construction of evaluation model of innovation and entrepreneurship education capability in colleges and universities}

The entropy TOPSIS is an effective multi-objective decision-making analysis method that combines the entropy weight method and the TOPSIS method, assigns weights to a limited number of evaluation objects, and performs relative merit evaluation. In the multi-index evaluation, the entropy weight method judges whether the effect of the evaluation index is significant by the same index's difference in value of different evaluation objects and highlights the weight of the local difference judgment index, and the greater the difference in the index is, the greater role it plays in the evaluation process. The TOPSIS method is a multi-objective decisionmaking method (Hwang \& Yoon, 1981) and its core idea is to calculate the optimal solution and the worst solution of the evaluation objects, compare the evaluation objects with the best and worst solutions, calculate the similarity between the evaluation objects and the ideal solution and thus rank on the good and bad (Stewart, 1992). The range of closeness is between 0 and 1 , and the closer the value is, the closer the evaluation object is to the optimal level. The biggest advantage of this method is that it requires less sample size, which is easy to calculate.

The calculation steps of the entropy TOPSIS method are as follows:

First, construct judgment matrix

Assume that there are $\mathrm{m}$ programs and $\mathrm{n}$ indexes, thus forming a judgement matrix of $\mathrm{m}$ programs and $\mathrm{n}$ indexes: $A_{1}, A_{2}, \ldots, A_{m}$ represents $\mathrm{m}$ programs, $C_{1}, C_{2}, \ldots, C_{n}$ is $\mathrm{n}$ indexes.

$\mathrm{x}_{\mathrm{ij}}(\mathrm{i}=1,2, \ldots, \mathrm{n} ; \mathrm{j}=1,2, \ldots, \mathrm{m})$ is the observed value of the $\mathrm{jth}$ index of the ith evaluation object, and the obtained matrix is normalized to obtain:

$$
b_{i j}=\frac{x_{i j}-x_{\min }}{x_{\max }-x_{\min }}
$$

Second, determine entropy weight

$$
H_{j}=-\frac{1}{\ln m}\left(\sum_{j=1}^{m} f_{i j} \ln f_{i j}\right)
$$




$$
\begin{aligned}
& f_{i j}=\frac{b_{i j}}{\sum_{j=1}^{m} b_{i j}}(i=1,2, \ldots, n ; j=1,2, \ldots, m) \\
& \omega_{j}=\frac{1-H_{j}}{n-\sum_{j=1}^{n} H_{j}} \sum_{\text {and }}^{n} \omega_{j}=1
\end{aligned}
$$

Third, determine the ideal solution

$$
\begin{aligned}
& S^{+}=\left\{S_{j}^{+}=\max _{1 \leq i \leq m}\left(v_{i j}\right)\right\} j=1,2, \ldots, n \\
& S-=\left\{S_{j}^{-}=\min _{1 \leq i \leq m}\left(v_{i j}\right)\right\} j=1,2, \ldots, n
\end{aligned}
$$

Fourth, calculate Euclidean distance

$$
\begin{aligned}
& D^{+}=\sqrt{\sum_{j=1}^{n}\left[\omega_{j} \times\left(S_{j}^{+}-r_{i j}\right)\right]^{2}} i=1,2, \ldots m \\
& D^{-}=\sqrt{\sum_{j=1}^{n}\left[\omega_{j} \times\left(S_{j}^{-}-r_{i j}\right)\right]^{2}} i=1,2, \ldots m
\end{aligned}
$$

Fifth, calculate relative proximity

$$
c_{i}=\frac{D_{i}^{-}}{D_{i}^{+}+D_{i}^{-}} i=1,2, \ldots m
$$

\section{Empirical Research}

\section{Data sources}

In order to enhance the quality of innovation and entrepreneurship education in colleges and universities, this study selects 9 colleges and universities in Jiangsu Province that have done well in innovation and entrepreneurship education. They are Nanjing University, Southeast University, Nanjing University of Aeronautics and Astronautics, Soochow University, Hohai University, Nanjing University of Science and Technology, Nanjing Medical University, China University of Mining and Technology, and Nanjing Tech University. This study mainly selects the related data on innovation and entrepreneurship in 2016 from these nine colleges and universities for evaluation analysis. The data comes from The Top 50 Universities Received a Patent Grant in 2016 by the Science and Technology Development Center of the Ministry of Education, 2016 Compilation of Science and Technology Statistics in Colleges and Universities by the Science and Technology Division of the Ministry of Education, 2016 National Undergraduate Innovation and Entrepreneurship Training Program Project List on the official website of the Ministry of Education, 2016 National College Student Entrepreneurship Training Project and Entrepreneurship Practice Project List by the Ministry of 
Education's Higher Education Department, the official website of the Challenge Cup, and the official websites of universities and related statistical reports.

\section{Application of evaluation model}

The target layer, criterion layer, and index layer constitute the evaluation index system for innovation and entrepreneurship education in colleges and universities. This study uses entropy TOPSIS model to evaluate the three criterion layers of innovation and entrepreneurship education in colleges and universities, including basic environmental ability, resource allocation ability and result performance ability.

Table 2

Normalized Matrix Index Value

\begin{tabular}{lcccccccccccc}
\hline School & $\mathrm{X} 1$ & $\mathrm{X} 2$ & $\mathrm{X} 3$ & $\mathrm{X} 4$ & $\mathrm{X} 5$ & $\mathrm{X} 6$ & $\mathrm{X} 7$ & $\mathrm{X} 8$ & $\mathrm{X} 9$ & $\mathrm{X} 10$ & $\mathrm{X} 11$ & $\mathrm{X} 12$ \\
\hline U1 & 0.2222 & 1 & 0.7299 & 0.7050 & 0.6666 & 0.6590 & 0.4451 & 0.7 & 0.6666 & 0.9874 & 0.5165 & 1 \\
U2 & 0.1111 & 0.0049 & 0.7737 & 0.8444 & 1 & 0.7272 & 0.7368 & 0.4 & 0.125 & 0.9779 & 0.2561 & 0.4 \\
U3 & 0.4444 & 0.4586 & 0.9197 & 0.4814 & 0.4242 & 0.3409 & 0.6917 & 0.7 & 0.9583 & 0.9732 & 0.5991 & 0.9142 \\
U4 & 0.6666 & 0.4636 & 0.6642 & 0.7455 & 0.8181 & 0.5454 & 0.4541 & 0.8 & 0.8333 & 0.9827 & 1 & 0.5428 \\
U5 & 0.6666 & 0.0074 & 0.1751 & 0.1777 & 0.3939 & 0.3409 & 0.1684 & 0.1 & 0.4166 & 0.9654 & 0.1239 & 0.3142 \\
U6 & 1 & 0.2970 & 0.9416 & 0.9533 & 0.3939 & 0.2954 & 0.8796 & 0.5 & 1 & 1 & 0.4008 & 0.3428 \\
U7 & 0.2222 & 0.1957 & 1 & 1 & 0.2727 & 0.2272 & 1 & 1 & 1 & 0.9638 & 0.3512 & 0.2285 \\
U8 & 0.1111 & 0.2647 & 0.9416 & 0.9629 & 0.1818 & 0.1136 & 0.8616 & 0.4 & 0.125 & 0.9166 & 0.2190 & 0.4571 \\
U9 & 1 & 0.0602 & 0.1605 & 0.1629 & 0.3333 & 1 & 0.1518 & 0.2 & 0.125 & 0.9591 & 0.1033 & 0.2285 \\
\hline
\end{tabular}

Note. the U1 - U9 represent the Nanjing University, Southeast University, Nanjing University of Aeronautics \& Astronautics, Soochow University, Hohai University, Nanjing Medical University, China University of Mining and Technology, and Nanjing Tech University.

Table 3

Entropy Values, Coefficient of Variation, and Weights of the Innovation and Entrepreneurship Education Capacity

\begin{tabular}{|c|c|c|c|c|c|c|c|c|c|c|c|c|}
\hline Index & $\mathrm{X} 1$ & $\mathrm{X} 2$ & $\mathrm{X} 3$ & $\mathrm{X} 4$ & $\mathrm{X} 5$ & X6 & $\mathrm{X7}$ & $\mathrm{X} 8$ & $\mathrm{X9}$ & $\mathrm{X} 10$ & $\mathrm{X} 11$ & $\mathrm{X} 12$ \\
\hline $\mathrm{H}_{\mathrm{J}}$ & 0.8896 & 0.7878 & 0.9456 & 0.9420 & 0.9430 & 0.9278 & 0.9377 & 0.9328 & 0.8940 & 0.9998 & 0.9051 & 0.9386 \\
\hline $\mathrm{F}_{\mathrm{ij}}$ & 0.1104 & 0.2122 & 0.0544 & 0.0580 & 0.0570 & 0.0722 & 0.0623 & 0.0672 & 0.1060 & 0.0002 & 0.0949 & 0.0614 \\
\hline $\mathrm{W}_{\mathrm{j}}$ & 0.1155 & 0.2219 & 0.0569 & 0.0606 & 0.0595 & 0.0755 & 0.0651 & 0.0702 & 0.1108 & 0.0001 & 0.0992 & 0.0642 \\
\hline
\end{tabular}

Table 4

Euclidean Distance of Innovation and Entrepreneurship Education Capacity in Colleges and Universities

\begin{tabular}{lcccccccccccc}
\hline School & $\mathrm{X} 1$ & $\mathrm{X} 2$ & $\mathrm{X} 3$ & $\mathrm{X} 4$ & $\mathrm{X} 5$ & $\mathrm{X} 6$ & $\mathrm{X} 7$ & $\mathrm{X} 8$ & $\mathrm{X} 9$ & $\mathrm{X} 10$ & $\mathrm{X} 11$ & $\mathrm{X} 12$ \\
\hline U1 & 0.2222 & 1 & 0.7299 & 0.7050 & 0.6666 & 0.6590 & 0.4451 & 0.7 & 0.6666 & 0.9874 & 0.5165 & 1 \\
U2 & 0.1111 & 0.0049 & 0.7737 & 0.8444 & 1 & 0.7272 & 0.7368 & 0.4 & 0.125 & 0.9779 & 0.2561 & 0.4 \\
U3 & 0.4444 & 0.4586 & 0.9197 & 0.4814 & 0.4242 & 0.3409 & 0.6917 & 0.7 & 0.9583 & 0.9732 & 0.5991 & 0.9142 \\
U4 & 0.6666 & 0.4636 & 0.6642 & 0.7455 & 0.8181 & 0.5454 & 0.4541 & 0.8 & 0.8333 & 0.9827 & 1 & 0.5428 \\
U5 & 0.6666 & 0.0074 & 0.1751 & 0.1777 & 0.3939 & 0.3409 & 0.1684 & 0.1 & 0.4167 & 0.9654 & 0.1239 & 0.3142 \\
U6 & 1 & 0.2970 & 0.9416 & 0.9533 & 0.3939 & 0.2954 & 0.8796 & 0.5 & 1 & 1 & 0.4008 & 0.3428 \\
U7 & 0.2222 & 0.1957 & 1 & 1 & 0.2727 & 0.2272 & 1 & 1 & 1 & 0.9638 & 0.3512 & 0.2285 \\
U8 & 0.1111 & 0.2647 & 0.9415 & 0.9629 & 0.1818 & 0.1136 & 0.8616 & 0.4 & 0.125 & 0.9166 & 0.2190 & 0.4571 \\
U9 & 1 & 0.0602 & 0.1605 & 0.1629 & 0.3333 & 1 & 0.1518 & 0.2 & 0.125 & 0.9591 & 0.1033 & 0.2285 \\
\hline
\end{tabular}

(1) According to Equation (1), the evaluation object data are normalized to obtain a judgment matrix $b_{i j}$ (Table 2).

(2) According to Equations (1)-(4) and the normalized judgment matrix $b_{\mathrm{ij}}$, evaluation index entropy $\left(\mathrm{H}_{\mathrm{J}}\right)$, coefficient of variation $\left(\mathrm{F}_{\mathrm{ij}}\right)$, and weight $\left(\mathrm{W}_{\mathrm{j}}\right)$ can be obtained. The entropy values, coefficient of variation, and weights of the innovation and entrepreneurship education capacity in nine universities are shown in Table 3. 
(3) Equations (5) - According to the type of normalized judgment matrix all take a maximum, minimum value ideal solution and negative ideal solution are calculated respectively, further by type (6), (7) to the positive and negative ideal solution is 9 universities of Euclidean distance and various universities are relatively close to ci specific see table 4 and table 5 .

Table 5

Relative Proximity of Innovation and Entrepreneurship Education Capacity in Colleges and Universities

\begin{tabular}{|c|c|c|c|c|c|c|}
\hline \multirow[b]{2}{*}{ Index } & \multicolumn{2}{|c|}{$\begin{array}{l}\text { Basic environmental ability of } \\
\text { innovation and } \\
\text { entrepreneurship education }\end{array}$} & \multicolumn{2}{|c|}{$\begin{array}{l}\text { Resource allocation ability of } \\
\text { innovation and } \\
\text { entrepreneurship education }\end{array}$} & \multicolumn{2}{|c|}{$\begin{array}{l}\text { Result performance ability of } \\
\text { innovation and } \\
\text { entrepreneurship education }\end{array}$} \\
\hline & $\begin{array}{c}\text { Euclidean } \\
\text { distance of } \\
\text { negative ideal } \\
\text { solution }\end{array}$ & $\begin{array}{l}\text { Euclidean } \\
\text { distance of } \\
\text { ideal } \\
\text { solution } \\
\end{array}$ & $\begin{array}{c}\text { Euclidean } \\
\text { distance of } \\
\text { negative ideal } \\
\text { solution } \\
\end{array}$ & $\begin{array}{l}\text { Euclidean } \\
\text { distance of } \\
\text { ideal } \\
\text { solution } \\
\end{array}$ & $\begin{array}{c}\text { Euclidean } \\
\text { distance of } \\
\text { negative ideal } \\
\text { solution }\end{array}$ & $\begin{array}{l}\text { Euclidean } \\
\text { distance of } \\
\text { ideal } \\
\text { solution } \\
\end{array}$ \\
\hline U1 & 0.4967 & 0.2041 & 0.8466 & 0.0679 & 0.9853 & 0.5353 \\
\hline U2 & 0.1188 & 0.5364 & 0.7764 & 0.2178 & 0.2363 & 0.2851 \\
\hline U3 & 0.2587 & 0.3074 & 0.1423 & 0.6149 & 0.5955 & 0.9360 \\
\hline U4 & 0.2827 & 0.2802 & 0.2134 & 0.7594 & 0.0565 & 0.4644 \\
\hline U5 & 0.1410 & 0.5141 & 0.1119 & 0.6580 & 0.0281 & 0.4935 \\
\hline U6 & 0.3030 & 0.3431 & 0.2917 & 0.1843 & 0.4354 & 0.0854 \\
\hline U7 & 0.1814 & 0.4392 & 0.1817 & 0.2114 & 0.5204 & 0.0150 \\
\hline U8 & 0.1922 & 0.4238 & 0.2029 & 0.5115 & 0.4526 & 0.0697 \\
\hline U9 & 0.2272 & 0.4833 & 0.5672 & 0.2461 & 0.0134 & 0.5204 \\
\hline
\end{tabular}

Table 6

Comprehensive Evaluation Results

\begin{tabular}{|c|c|c|c|c|c|c|}
\hline \multirow[t]{2}{*}{ Index } & \multicolumn{2}{|c|}{$\begin{array}{c}\text { Basic environmental ability of } \\
\text { innovation and } \\
\text { entrepreneurship education }\end{array}$} & \multicolumn{2}{|c|}{$\begin{array}{l}\text { Resource allocation ability of } \\
\text { innovation and } \\
\text { entrepreneurship education }\end{array}$} & \multicolumn{2}{|c|}{$\begin{array}{l}\text { Result performance ability of } \\
\text { innovation and } \\
\text { entrepreneurship education }\end{array}$} \\
\hline & $\begin{array}{l}\text { Relative } \\
\text { proximity }\end{array}$ & Ranking & $\begin{array}{l}\text { Relative } \\
\text { proximity }\end{array}$ & Ranking & $\begin{array}{l}\text { Relative } \\
\text { proximity }\end{array}$ & Ranking \\
\hline U1 & 0.7087 & 1 & 0.8398 & 1 & 0.6479 & 6 \\
\hline $\mathrm{U} 2$ & 0.1813 & 9 & 0.3185 & 7 & 0.8126 & 4 \\
\hline U3 & 0.4570 & 4 & 0.4373 & 5 & 0.3888 & 7 \\
\hline U4 & 0.5022 & 2 & 0.5189 & 2 & 0.6946 & 5 \\
\hline U5 & 0.2153 & 8 & 0.0095 & 9 & 0.0185 & 8 \\
\hline U6 & 0.4690 & 3 & 0.4668 & 3 & 0.9438 & 3 \\
\hline U7 & 0.2923 & 7 & 0.4294 & 6 & 0.9901 & 1 \\
\hline U8 & 0.3120 & 6 & 0.4522 & 4 & 0.9541 & 2 \\
\hline U9 & 0.3198 & 5 & 0.0480 & 8 & 0.0087 & 9 \\
\hline
\end{tabular}

Table 7

Comprehensive Evaluation Results

\begin{tabular}{lcc}
\hline Colleges and universities & Total relative proximity & Ranking \\
\hline U1 & 0.6721 & 1 \\
U2 & 0.2601 & 3 \\
U3 & 0.5204 & 2 \\
U4 & 0.5727 & 9 \\
U5 & 0.2109 & 4 \\
U6 & 0.4912 & 5 \\
U7 & 0.4048 & 7 \\
U8 & 0.2914 & 6 \\
U9 & 0.3098 & \\
\hline
\end{tabular}

(5) The above analysis makes a careful evaluation and comparison of the basic environmental ability, resource allocation ability, and result performance capability of innovation and entrepreneurship education, but fails to complete the evaluation of innovation and entrepreneurship education capacity of colleges and universities under the combined impact of the three criterion layers. For this reason, this study reconstructs the 
model and integrates the three criterion layer factors into the evaluation criteria. The specific evaluation process is consistent with the evaluation process of each criterion layer. After calculation, the total relative proximity of the innovation and entrepreneurship education capacity in 9 colleges and universities can be obtained (Table 7).

\section{Analysis of evaluation results}

\section{Dimensional analysis}

According to the basic principle of entropy weight, the greater value of entropy weight indicates that the index can provide more effective information for decision makers; on the contrary, it provides less effective information. The entropy weights of the indexes in Table 3 mainly fluctuate around $\omega=0.07$, so we set $\omega=0.07$ as the entropy weight limit, and the indexes with entropy weight of greater than 0.07 as the main factors affecting innovation and entrepreneurship education capacity of colleges and universities. The indexes with entropy weight of less than 0.07 are general or secondary factors.

(1) Analysis on the basic environment of innovation and entrepreneurship education capacity

For the index X1 (the number of publications related to innovation and entrepreneurship), the X2 (the number of granted patents), the entropy weight $\omega$ is all greater than 0.07 , and is 0.1155 and 0.2219 , respectively, indicating that these indexes provide more information for the environmental basis of innovation and entrepreneurship education and make significant contributions to the basic ability of the environment of innovation and entrepreneurship education and they are major factors. Among them, the index X2 (the number of granted patents) is the largest index of entropy weight in the entire evaluation index system and contributes the most to innovation and entrepreneurship education capacity in colleges and universities; the indexes X3 (the number of initiated innovation and entrepreneurship program projects) and X4 (the grants of innovation and entrepreneurship program projects) are general influence factors.

Nanjing University, Nanjing University of Aeronautics and Astronautics, and Soochow University performed the most significantly under the index of the number of granted patents with the highest entropy weight (X2), indicating that these three universities have a good foundation for innovation and entrepreneurship education, and have a significant multiplier effect on the comprehensive innovation and entrepreneurship education capacity. When the number of publications and the number of granted patents related to innovation and entrepreneurship increase or decrease, the comprehensive innovation and entrepreneurship education capacity can be doubled or weakened. Nanjing University of Science and Technology and Nanjing Tech University also performed more significantly under the index of the number of publications on innovation and entrepreneurship (X1), which shows that the basic environmental ability of innovation and entrepreneurship education has been improved in the number of publications and the number of granted patents related to innovation and entrepreneurship education. It is a good example that other colleges and universities can start with these two indexes to improve the basic environmental ability of innovation and entrepreneurship education.

(2) Analysis of the Resources Allocation Ability of Innovation and Entrepreneurship Education in Colleges and Universities

The entropy weights $(\omega)$ of index X6 (the number of innovation and entrepreneurship education courses offered by universities) and $\mathrm{X} 8$ (the number of entrepreneurship parks for college students) are all greater than 0.07 , and they are 0.0755 and 0.0702 , respectively. Therefore, these indexes can be defined as can be defined as the main factors affecting the resource allocation ability of innovation and entrepreneurship education of colleges and universities. The entropy weights of indexes X5 (the number of teachers in the innovation and entrepreneurship courses) and $\mathrm{X} 7$ (the number of participants in the innovation and entrepreneurship program) are close to 0.07 , indicating that there is little variation in the index values under this criterion, and there is no 
significant difference in the performance of all nine universities. From the statistical data, the colleges and universities that rank first in comprehensive innovative entrepreneurship education ability such as Nanjing University, Southeast University, Soochow University, and others perform well in the number of innovative and entrepreneurial education courses, the number of entrepreneurship parks for college students, the number of teachers for innovation and entrepreneurship course, and the number of students participating in the national entrepreneurship program. This indicates that these colleges and universities pay more attention to improve the innovation and entrepreneurship education ability of colleges and universities with the combination of the theoretical and practice and through innovation and entrepreneurship courses, entrepreneurial program projects, entrepreneurship parks and others. Besides, Nanjing Tech University has the largest number of innovation and entrepreneurship education courses and pays the most attention to the guiding role of values in theoretical courses.

(3) Analysis on the result performance ability of innovation and entrepreneurship education in colleges and universities

The entropy weights of the index X9 (the number of awards in Challenge Cup Entrepreneurial Planning Competition) and the X11 (the number of incubator enterprises in entrepreneurship parks) are more than 0.07 , and are 0.1108 and 0.0992 respectively, which are the main influence factors in the criterion layer. At the same time, the entropy weight of these 2 indexes is second only to the maximum entropy weight index X2 (the number of granted patents). Therefore, the indexes X9 and X11 have a significant effect on improving the comprehensive innovation and entrepreneurship education ability.

Soochow University performs well on index X11 (the number of incubator enterprises in entrepreneurship parks) and leaves an obvious gap away from other universities. This shows that the university attaches great importance to the education and training of start-up companies, incubation services, and the combination of production, study, and research and has made tremendous contributions to cultivating many high-quality innovation and entrepreneurship talents, creating high-tech enterprises and entrepreneurs, and nurturing new economic growth points based on high-tech enterprise groups.

The entropy weight $\omega$ of the index X10 (psychological characteristics of college students' innovation and entrepreneurship) is 0.0001 , and is the lowest in the index layer, indicating that students from 9 colleges and universities have similar psychological characteristics in innovation, relationships, communication, leadership, psychology flexibility, adaptation, and success, and there is no significant difference. Analysis of the index X12 (the number of outstanding innovation and entrepreneurship alumni) shows that there are slight differences in the number of outstanding alumni among colleges and universities, which indicates that colleges and universities export a large number of high-quality entrepreneurship entrepreneurs and reserves a large number of reserve talents for the sustained and stable growth of China's economy.

\section{Overall analysis}

According to the principle of TOPSIS law, the closer the evaluation objects' proximity is, the stronger the innovation and entrepreneurship education ability in colleges and universities is. Generally, Nanjing University's innovation and entrepreneurship education ability ranks first among 9 universities, followed by Soochow University and Nanjing University of Aeronautics and Astronautics. Overall evaluation results are consistent with the objective reality. According to the relative proximity ci value, 9 colleges and universities can be divided into 3 categories:

Category I: ci $\geq 0.5$, including 3 colleges and universities such as Nanjing University, Soochow University, and Nanjing University of Aeronautics and Astronautics. With the outstanding advantages of the granted patents, the practical platform and the support of scientific and technological talents, these universities take a lead in innovation and entrepreneurship education ability in 9 colleges and universities. Among them, Nanjing 
University demonstrates its significant advantages in the evaluation of innovation and entrepreneurship education capacity, indicating that it places greater emphasis on the application ability of innovation and entrepreneurship knowledge and the transformation of scientific research results. From Table 5, it can be seen that Nanjing University and other two universities have the most outstanding total relative proximity and take a lead in basic environmental ability and resource allocation ability, but their result performance ability is weak, indicating that input and output have not reached equilibrium, and resource allocation capacity needs to be improved in order to achieve full and efficient use of the resources for innovation and entrepreneurship education and maximize the conversion rate of input and output.

Category II: $0.29<\mathrm{ci}<0.5$, including Nanjing University of Science and Technology, Nanjing Medical University, China University of Mining and Technology, and Nanjing Tech University, which have average innovation and entrepreneurship education capacity. These colleges and universities have relative advantages and disadvantages in one aspect, which leads to them in the middle ranking. For example, Nanjing University of Science and Technology develops balance in education environment foundation, allocation of resources and result performance, its resource allocation is better, and the resource input and output are equal; the Nanjing Medical University is worse in the education environment foundation and resource allocation, but the result performance ranks among the first universities. From the original data, it can be found that the university has high emphasis on the entrepreneurial competition, pays more attention to cultivating the students' intention to start up a business, and increases the input on environmental foundation and resource allocation can bring the multiplier effect of the result performance ability.

Category III: ci $\leq 0.29$, including Southeast University and Hohai University, which belong to colleges below the average level of entrepreneurship education. The two universities are poor in the basic environmental ability of innovation and entrepreneurship education, and the resources allocation ability, which leads to the difficult transformation of output results and the weak result performance ability of the innovation and entrepreneurship education. Therefore, these colleges and universities should continue to exert their characteristics and advantages in the innovation and entrepreneurship course, play a positive role in promoting the innovation and entrepreneurship course and teaching in the theory and practice of innovation and entrepreneurship education, achieve the needs of the development of the subject and meet the needs of the social development, thus inspiring the enthusiasm of the teachers and students of colleges and universities for innovation and entrepreneurship.

\section{Conclusion}

The empirical analysis and evaluation of 9 colleges and universities in Jiangsu Province shows that the overall deepening of improving innovation and entrepreneurship education ability of colleges and universities in Chin is the value pursuit of the educational reform and the development of innovation and entrepreneurship education. Further research shows that: (1) the entropy TOPSIS model can scientifically and effectively reflect the implementation effect and the optimization direction of the existing problems in the innovation and entrepreneurship education of 9 colleges and universities. The results of the analysis can enhance the cognitive level of colleges and universities to the innovation and entrepreneurship education to a certain extent. (2) There are 2 main factors affecting the innovation and entrepreneurship education ability in both the environment foundation, resource allocation and result performance capacity. Among these main factors, the number of publications, the number of granted patents, the number of entrepreneurship program competitions, and the entropy of entrepreneurship parks in colleges and universities are close to 0.1000 , which explains the resource input of the 4 indexes has a strong pulling effect on the innovation and entrepreneurship education, while other factors also play a certain role in promotion. (3) The resource allocation ability of colleges and universities is different, with significantly different ratio of input to output. Although the innovation and entrepreneurship education in colleges and universities has shown a strong trend of development, their innovative and entrepreneurial education ability has the characteristics and differences in the environmental foundation, 
resource allocation and result performance factors. How to make a scientific and rational allocation of educational resources in colleges and universities has become the crux of the overall promotion of innovative entrepreneurship education.

Innovation and entrepreneurship education is an educational system project which operates jointly by the government, schools and society. It is necessary to establish an innovation and entrepreneurship education ecosystem, such as government, teachers, scientific research and science and technology parks (practical carriers), to avoid the short board effect of innovation and entrepreneurial environment. In addition, it is necessary to focus on the evaluation by college students on the effect of innovation and entrepreneurship education (Gibb, 2011), and to increase the policy support for the proportion of innovation and entrepreneurship education to teacher assessment and job title evaluation. Dependent on social and government-driven efforts, we should establish an "incubator" for innovation and entrepreneurship education to improve the survival rate of entrepreneurial ventures; through policy guidance, we should optimize the environment for mass entrepreneurship and promote the standardized development of maker space.

\section{References}

Gibb, A. (2011). Concepts into practice: meeting the challenge of development of entrepreneurship educators around an innovative paradigm: The case of the International Entrepreneurship Educators; Programme (IEEP). International Journal of Entrepreneurial Behaviour \& Research, 17(2), 146-165. http://dx.doi. org/10.1108/13552551111114914

Huang, Z., Zhao, G., \& Tang, W. (2015). On the transformation and development of education in universities in the era of entrepreneurship. Education Exploration, 125(7), 34-39.

Li, J. (2012). Research on the quality evaluation system of entrepreneurship education based on efficiency perspective. Science and Technology Management Research, 15, 145-149.

Li, Y., \& Wang, H. (2014). Design of education quality evaluation index system based on BSC. Technology and Management, 2014(16), 53-57.

Qin, J. (2009). Research on the quality evaluation of education based on QFD in universities. Tianjin: Tianjin University.

Song, S., Xu, M., \& Ning, Q. (2012). Quality evaluation system and empirical research of university entrepreneurship education. Journal of Hefei University of Technology (social science edition), 2012(10), 121-126.

Stewart, T. J. (1992). A critical survey on the status of multiple criteria decision making theory and practice. OMEGA, 1992(20), 569-586. http://dx.doi. org/10.1016/0305-0483(92)90003-P

Vesper, K. H., \& Gartner, W. B. (1997). Measuring progress in entrepreneurship education. Journal of Business Venturing, 12(5), 403-421. http://dx.doi. org/10.1016/S0883-9026(97)00009-8

Hwang, C. L., \& Yoon, K. (1981). Methods for multiple attribute decision making. In Multiple attribute decision making. Springer, Berlin, Heidelberg. 